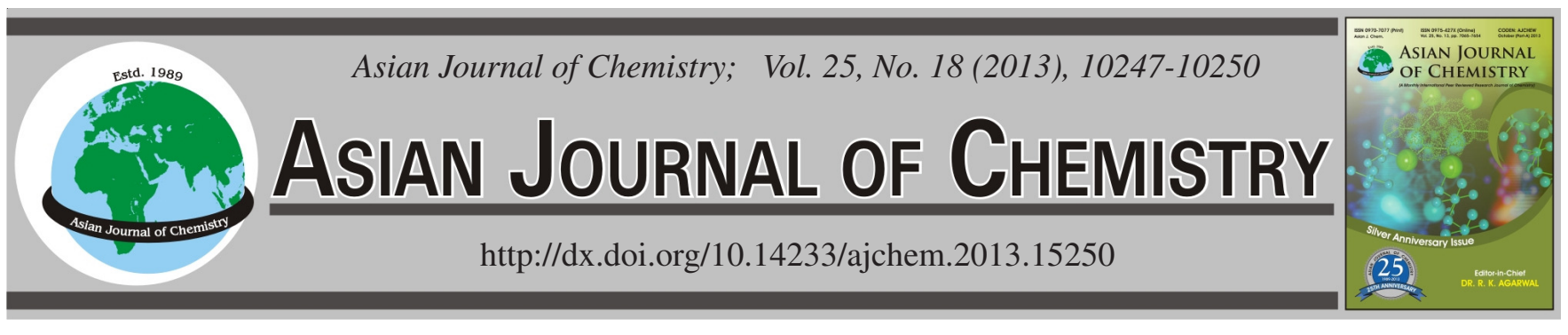

\title{
Volumetric and Transport Properties of Ternary Mixtures Containing Methyl benzoate + Cyclohexane + Hexanol at Different Temperature
}

\author{
M. UMADEVI ${ }^{1, *}$ and R. KeSAVASAMY ${ }^{2}$
}

${ }^{1}$ Department of Physics, SVS College of Engineering, Coimbatore-642 109, India

${ }^{2}$ Department of Physics, Sri Ramakrishna Engineering College, Coimbatore-641 022, India

*Corresponding author: Fax: +91 422 2321332; E-mail: devuma55@gmail.com

(Received: 31 January 2013;

Accepted: 11 November 2013)

\begin{abstract}
The volumetric and transport properties of ternary mixtures containing methyl benzoate + cyclohexane + hexanol have been investigated from the ultrasonic velocity $(\mathrm{U})$, density $(\rho)$, viscosity $(\eta)$ measurements at 303,308 and $313 \mathrm{~K}$. From the experimental data, adiabatic compressibility $(\beta)$, free length $\left(\mathrm{L}_{\mathrm{F}}\right)$, free volume $\left(\mathrm{V}_{\mathrm{F}}\right)$, internal pressure $\left(\pi_{\mathrm{i}}\right)$, have been calculated. In addition to that the excess values of above parameters are also evaluated. The excess properties have been used to discuss the presence of significant interactions between the component molecules in the ternary mixtures.
\end{abstract}

Key Words: Density, Viscosity, Adiabatic Compressibility, Excess values, Methyl benzoate, Cyclohexane, Hexanol.

\section{INTRODUCTION}

One of the main problems of the chemical industrial growth is the generation of hazardous waste. In fact, due to stricter environmental regulations, many industries have to carefully consider pollution prevention in order to minimize adverse environmental impact. Hazardous pollutants (HAP) and volatile organic compounds (VOCs) thermal emission control devices usually require large amounts of energy and non-thermal ones require additional maintenance. The former techniques use large capital investments in heat recovery options and the latter, replacement of costly consumables and energy to regenerate the adsorbent. These factors make the separation and destruction of volatile organic hazardous products (also defined as VOHAPs) from emissions an extremely energy-intensive task to perform. The VOHAPs include a wide range of individual substances, such as hydrocarbons, halocarbons and oxygenates that evaporate easily from water into air at normal air temperatures and are commonly used in industry for processes, such as degreasing, thinning and dissolving. Specifically, cyclohexane is a non-polar, it is a solvent and used in the production of nylon in the metal industry. In the last few years, new cleaning technologies proposed are a synergistic blend of general existing techniques strongly oriented for low concentration and nuisance odor VOHAPs emissions in air or liquid streams. These kind of technologies are used to convert hazardous wastes into non-hazardous or reusable products, converting VOHAPs into biomass and avoiding the inherent high costs of destruction.
Continuing our research on thermodynamic properties of mixtures related to industrial processes ${ }^{1-6}$, we present a new study of densities of the ternary mixtures (methyl benzoate + cyclohexane + hexanol) at 303, 308 and $313 \mathrm{~K}$ at atmospheric pressure. The free length, free volumes and the internal pressure were computed, an interpretation in terms of composition and molecular size being made. Volumetric and transport properties of liquid mixtures have been extensively used $^{7-9}$ to study the departure of a real liquid mixture behaviour from ideality. Further, these properties have been widely used to study the intermolecular interactions between the various species present in the mixture ${ }^{9-12}$. Therefore in order to have a clear understanding of the intermolecular interactions between the component molecules, a thorough study on the liquid mixtures using ultrasonic velocity data has been performed.

\section{EXPERIMENTAL}

All the chemicals used in the present work are Analar grade. The purity of the chemicals was ascertained by comparing their densities, viscosities and ultrasonic velocities at 303 , 308 and $313 \mathrm{~K}$ which agrees with the corresponding literature values. The mixtures of (methyl benzoate + cyclohexane + hexanol) were prepared by weight. The mole fraction of the second component, cyclohexane $\left(\mathrm{x}_{2}=0.4\right)$ was kept constant, while the mole fractions of the remaining two $\left(\mathrm{x}_{1}, \mathrm{x}_{3}\right)$ were varied from $0.1-0.6$. The ultrasonic velocity was measured by a single crystal interferometer with a high degree of accuracy operating at a frequency of $3 \mathrm{MHz}$ (model F-05, with digital 
micrometer) at 303,308 and $313 \mathrm{~K}$. The viscosity was measured by Ostwald's viscometer. An electronically operated constant temperature water bath is used to circulate water through the double walled measuring cell made up of steel containing the experimental solution at the desired temperature. Densities of the mixtures have been found by relative measurement method.

Theory and calcutations: Intermolecular free length $\left(\mathrm{L}_{\mathrm{F}}\right)$ is calculated using the standard expression

$$
\mathrm{L}_{\mathrm{F}}=\mathrm{K} \beta^{1 / 2}
$$

where $\mathrm{K}$ is a temperature dependent constant known as Jacobson constant and $\beta$ is the adiabatic compressibility that can be calculated from the speed of sound (U) and the density of the medium $(\rho)$ as

$$
\beta=\frac{1}{U^{2} \rho}
$$

The relation for free volume in terms of ultrasonic velocity (U) and the viscosity $(\eta)$ of the liquid as

$$
\mathrm{V}_{\mathrm{F}}=\left(\frac{\mathrm{M}_{\mathrm{eff}} \mathrm{U}}{\eta \mathrm{K}}\right)^{3 / 2}
$$

Expression for the determination of internal pressure $\left(\pi_{\mathrm{i}}\right)$ by the use of free volume $\left(\mathrm{V}_{\mathrm{F})}\right)$ as

$$
\pi_{\mathrm{i}}=\mathrm{bRT}\left(\frac{\mathrm{K} \eta}{\mathrm{U}}\right)^{1 / 2}\left(\frac{\rho^{2 / 3}}{M_{\mathrm{eff}}^{7 / 6}}\right)
$$

where $b$ stands for cubic packing which is assumed to be 2 for liquids and $\mathrm{K}$ is a dimensionless constant independent of temperature and nature of liquids and its value is $4.281 \times 10^{9}$, $\mathrm{T}$ is the absolute temperature and $\mathrm{M}_{\mathrm{eff}}$ is the effective molecular weight.

In order to study the non-ideality of the liquid mixtures, namely excess parameters $\left(\mathrm{A}^{\mathrm{E}}\right)$ of all the acoustic parameter were computed by

$$
\begin{array}{r}
\mathrm{A}^{\mathrm{E}}=\mathrm{A}_{\exp }-\mathrm{A}_{\mathrm{id}} \\
\mathrm{A}_{\mathrm{id}}=\sum \mathrm{A}_{\mathrm{i}} \mathrm{X}_{\mathrm{i}}
\end{array}
$$

where

$A_{i}$ is any acoustical parameter and $x_{i}$ is the mole fraction of the liquid components.

\section{RESULTS AND DISCUSSION}

In this work the density $(\rho)$, viscosity $(\eta)$ and ultrasonic velocity $(\mathrm{U})$ of the mixtures of methyl benzoate + cyclohexane + hexanol at different temperatures have been measured and given in the Table-1. From these observed values various acoustical parameters like adiabatic compressibility $(\beta)$, free length $\left(\mathrm{L}_{\mathrm{F}}\right)$, free volume $\left(\mathrm{V}_{\mathrm{F}}\right)$, internal pressure $\left(\pi_{\mathrm{i}}\right)$, have been evaluated and it is presented in the Table-2. Excess values are depicted in Table-3. These data were correlated by polynomial expressions which fits the data well.

Table-1 showed that the ultrasonic velocity, density of the ternary liquid mixtures decreases with increasing mole fraction of hexanol while the viscosity increases. However the ultrasonic velocity, density, viscosity decreases in all the cases as temperature increases. The same result was obtained by previous workers ${ }^{13-15}$. Methyl benzoate is an industrial ester, alcohols are polar liquids strongly associated with hydrogen bonding, with an extent of polymerization that may differ depending on temperature, chain length and position of $\mathrm{OH}$ group.

When the compounds are mixed, the changes that occur in association equilibrium were evidently due to the rupture of the hydrogen bonds in pure cyclohexane, hexanol and methyl benzoate. It is well known that hexanol forms a variety of a species with different degree of association in the pure state. However, polymeric linear associates are expected to be predominant in the pure state. Thus, the addition of methyl benzoate to a hexanol may result in the following effects: (i)

\begin{tabular}{|c|c|c|c|c|c|c|c|c|c|c|c|}
\hline \multicolumn{3}{|c|}{ Adiabatic compressibility $\beta \times 10^{-10} \mathrm{~m}^{2} / \mathrm{N}$} & \multicolumn{3}{|c|}{ Free length $\mathrm{L}_{\mathrm{F}} \times 10-{ }^{10} \mathrm{~m}$} & \multicolumn{3}{|c|}{ Free volume $\mathrm{V}_{\mathrm{F}} \times 10^{7}\left(\mathrm{~m}^{3} \mathrm{~mol}^{-1}\right)$} & \multicolumn{3}{|c|}{ Internal pressure $\pi_{\mathrm{i}} \times 10^{6}$} \\
\hline $303 \mathrm{~K}$ & $308 \mathrm{~K}$ & $313 \mathrm{~K}$ & $303 \mathrm{~K}$ & $308 \mathrm{~K}$ & $313 \mathrm{~K}$ & $303 \mathrm{~K}$ & $308 \mathrm{~K}$ & $313 \mathrm{~K}$ & $303 \mathrm{~K}$ & $308 \mathrm{~K}$ & $313 \mathrm{~K}$ \\
\hline 6.34 & 6.48 & 6.76 & 0.50 & 0.51 & 0.53 & 2.25 & 2.41 & 2.52 & 339.93 & 337.30 & 336.73 \\
\hline 5.56 & 5.90 & 6.23 & 0.47 & 0.49 & 0.51 & 2.00 & 2.12 & 2.31 & 354.43 & 352.76 & 348.12 \\
\hline 6.03 & 6.39 & 6.60 & 0.49 & 0.51 & 0.52 & 1.79 & 1.90 & 2.09 & 367.76 & 365.38 & 359.15 \\
\hline 6.70 & 7.22 & 7.43 & 0.52 & 0.54 & 0.55 & 1.31 & 1.40 & 1.50 & 405.35 & 401.69 & 399.10 \\
\hline 7.00 & 7.62 & 7.80 & 0.53 & 0.55 & 0.57 & 1.19 & 1.23 & 1.30 & 430.63 & 422.93 & 419.84 \\
\hline 7.72 & 8.05 & 8.52 & 0.55 & 0.57 & 0.59 & 0.81 & 0.88 & 0.95 & 479.54 & 473.98 & 466.90 \\
\hline 8.29 & 8.92 & 9.28 & 0.57 & 0.60 & 0.62 & 0.54 & 0.61 & 0.63 & 551.12 & 546.22 & 537.31 \\
\hline
\end{tabular}
rupturing or disruption of associate structures in alcohols, (ii)

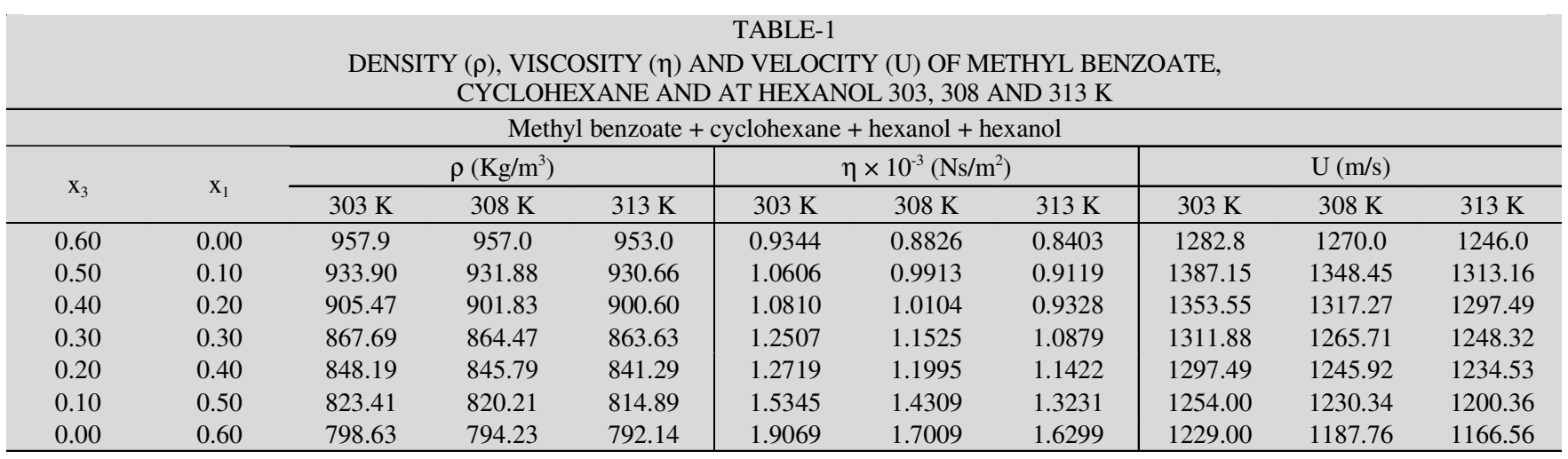

TABLE-2

ADIABATIC COMPRESSIBILITY ( $\beta$ ), FREE LENGTH $\left(\mathrm{L}_{\mathrm{F}}\right)$ AND FREE VOLUME $\left(\mathrm{V}_{\mathrm{F}}\right)$ OF METHYL BENZOATE, CYCLOHEXANE AND HEXANOL AT 303, 308 AND 313K 
TABLE-3

EXCESS ADIABATIC COMPRESSIBILITY $\left(\beta^{\mathrm{E}}\right)$, EXCESS FREE LENGTH $\left(\mathrm{L}_{\mathrm{F}}^{\mathrm{E}}\right)$, EXCESS FREE VOLUME $\left(\mathrm{V}_{\mathrm{F}}^{\mathrm{E}}\right)$ AND EXCESS INTERNAL PRESSURE $\left(\pi_{\mathrm{i}}{ }^{\mathrm{E}}\right)$ OF METHYL BENZOATE, CYCLOHEXANE AND HEXANOL AT 303, 308 AND $313 \mathrm{~K}$

\begin{tabular}{|c|c|c|c|c|c|c|c|c|c|c|c|}
\hline \multicolumn{3}{|c|}{$\begin{array}{l}\text { Excess adiabatic compressibility } \\
\qquad \beta \times 10^{-10} \mathrm{~m}^{2} / \mathrm{N}\end{array}$} & \multicolumn{3}{|c|}{$\begin{array}{l}\text { Excess free length } \\
\mathrm{L}_{\mathrm{F}} \times 10^{-10} \mathrm{~m}\end{array}$} & \multicolumn{3}{|c|}{$\begin{array}{l}\text { Excess free volume } \\
\mathrm{V}_{\mathrm{F}} \times 10^{-7}\left(\mathrm{~m}^{3} \mathrm{~mol}^{-1}\right)\end{array}$} & \multicolumn{3}{|c|}{$\begin{array}{l}\text { Excess internal } \\
\text { pressure } \pi_{\mathrm{i}} \times 10^{6}\end{array}$} \\
\hline $303 \mathrm{~K}$ & $308 \mathrm{~K}$ & $313 \mathrm{~K}$ & $303 \mathrm{~K}$ & $308 \mathrm{~K}$ & $313 \mathrm{~K}$ & $303 \mathrm{~K}$ & $308 \mathrm{~K}$ & $313 \mathrm{~K}$ & $303 \mathrm{~K}$ & $308 \mathrm{~K}$ & $313 \mathrm{~K}$ \\
\hline-0.16 & -0.32 & -0.34 & 0.00 & -0.01 & -0.01 & 0.72 & 0.74 & 0.67 & -49.01 & -45.70 & -38.13 \\
\hline-1.17 & -1.27 & -1.10 & -0.04 & -0.04 & -0.04 & 0.61 & 0.60 & 0.62 & -70.20 & -63.64 & -57.48 \\
\hline-0.94 & -0.98 & -0.96 & -0.03 & -0.03 & -0.03 & 0.73 & 0.73 & 0.79 & -132.6 & -122.9 & -112.6 \\
\hline-0.50 & -0.35 & -0.35 & -0.02 & -0.01 & -0.01 & 0.19 & 0.16 & 0.11 & -85.85 & -77.02 & -63.80 \\
\hline-0.43 & -0.15 & -0.21 & -0.01 & -0.01 & -0.01 & 0.21 & 0.12 & 0.06 & -91.71 & -84.92 & -69.87 \\
\hline 0.06 & 0.09 & 0.28 & 0.00 & 0.01 & 0.01 & -0.05 & -0.10 & -0.15 & -72.56 & -61.70 & -48.41 \\
\hline 0.39 & 0.76 & 0.81 & 0.01 & 0.03 & 0.03 & -0.21 & -0.25 & -0.34 & -29.72 & -16.37 & -2.76 \\
\hline
\end{tabular}

formation of new species because of interaction between ester and alcohols, (iii) free volume changes upon mixing of components of different sizes ${ }^{16}$.

Further the adiabatic compressibility, free length shows an inverse behaviour compared to the ultrasonic velocity in the mixtures (Table-2). It is primarily the compressibility that changes with the structure and this lead to the change in ultrasonic velocity. The addition of interacting molecules breaks up the molecular clustering of the other releasing several dipoles for the interactions.

In view of greater force of interaction between the molecules there will be an increase in cohesive energy and the occurrence of structural changes takes place due to the existence of electrostatic field. Thus structural arrangement of molecules results in increasing adiabatic compressibility thereby showing intermolecular interactions. Similar results in some liquid mixtures were also reported by others ${ }^{12-15}$.

Tables- 2 showed that as the concentration of primary alcohol increases, free volume decreases. Internal pressure increases with increase in concentration of alcohol. However, with rise in temperature increase in free volume and decrease in internal pressure are noticed. This suggests the closed packing of molecules inside the shield. Such an increase in internal pressure generally indicates association through hydrogen bonding and hence supports the present investigation. In the methyl benzoate structure there are a lot of voids available for $\mathrm{O}-\mathrm{H}$ to penetrate and enter into complexion and also provides information regarding the hydrogen bond between interacting components $^{16}$.

At high concentration of alcohol in the mixture, there are a large number of alcohol molecules surrounding the ester molecules. At low concentration of alcohol in the mixtures, there are only a small number of alcohol molecules to enable dipole-dipole interaction through hydrogen bonding with the non associative ester molecules. The associative alcohol molecules act as proton donor enabling hydrogen bonding with methyl benzoate molecules.

In order to understand more about the nature of the interaction between the components of liquid mixture, it is necessary to discuss the same in terms of excess parameters rather than the actual values. They can yield an idea about the non linearity of the system as association or other type of interactions ${ }^{17}$. Sridevi et al. ${ }^{13}$, suggested that the negative excess compressibility has been due to closed pack molecules and the positive excess values are due to weak interaction between the unlike molecules.
From the Table- 3 , the excess properties were found to decrease with increase in temperature. The value of excess inter molecular free length follows the same trend as that of excess adiabatic compressibility. The value of excess inter molecular free length are negative. According to Saleh et al. ${ }^{18}$ the sign of excess molar volume depends upon the relative magnitude of contractive and expansive effects which arises on mixing of liquid components.

Mostly excess free volume values are small positive or negative for ternary mixtures. The results were conformed with the following ternary mixtures like 1-propanol + ethyl ethanoate + cyclohexane, 1-propanol + propylpropanoate + cyclohexane $^{19}$, methyl butanoate + heptane + cyclooctane $^{20}$, propyl propanoate + hexane + cyclohexane ${ }^{21}$ and 1-butanol + dioxane + cyclohexane $^{22}$ can probably be ascribed to the inefficient packing in the mixtures of these components as a result of their incompatible structures, cyclohexane with an arm-chair structure.

In the present work the excess free volume values shift from positive to negative as the amount of hexanol increases in the mixture, which indicates strong molecular interactions in this system for all the ternary mixtures. This may be due to the differences in molecular sizes of the components of the mixtures, dipole-dipole type forces ${ }^{23}$ resulting from the polarisability of ester molecules by the dipoles of the liquid components ${ }^{24}$ of the mixtures and donor-acceptor interaction. The negative excess internal pressure over the entire range of mole fraction of the system also supports the presence of interaction.

\section{Conclusion}

Components maintained their individuality in the mixture. It is well known that when non-polar compounds are mixed, slight variations in the intermolecular interactions takes place. The negative excess values over the entire range of mole fraction of the system supports the presence of strong interaction. All the experimental determinations of adiabatic compressibility, free volume, internal pressure and free length are strongly correlated with each other and supports for strong interaction.

\section{REFERENCES}

1. C. Gonzalez, M. Iglesias, J. Lanz and J.M. Resa, Thermochim. Acta, 328, 277 (1999).

2. G. Marino, B. Orge, M. Iglesias and J. Tojo, J. Chem. Eng. Data, 45, 457 (2000).

3. M.J. Fontao and M. Iglesias, Phys. Chem. Liq., 38, 623 (2000). 
4. L.M. Casas, A. Tourin o, G. Marino, M. Iglesias, B. Orge and J. Tojo, J. Chem. Eng. Data, 47, 887 (2002).

5. A. Tourino, M. Iglesias and G. Marino, J. Solution Chem., 31, 793 (2002).

6. M.J. Fontao and M. Iglesias, Int. J. Thermophys., 23, 513 (2002).

7. M.I. Aralaguppi and J.G. Barragi, J. Chem. Thermodyn., 38, 434 (2006).

8. R.T. Morrison and B.R. Nelson, Organic Chemistry. Prentice Hall of India Pvt. Ltd., New Delhi, edn. 6, p. 1071 (2001).

9. P.S. Niham, V.M. Kapade and M. Hasan, Indian J. Pure Appl. Phys., 38, 170 (2000).

10. M.S.S. Bhatti and C.D.P. Singh, Indian J. Pure Appl. Phys., 21, 506 (1983).

11. B.M. Rastogi, E.A. Awasthi, M. Guptha and J.P. Shukla, Indian J. Pure Appl. Phys., 40, 256 (2002).

12. G. Arul and L. Palaniappan, Indian J. Pure Appl. Phys., 39, 561 (2001).

13. U. Sridevi, K. Samatha and A. Viswanatha Sarma, J. Pure Appl. Ultrason., 26, 1 (2004)

14. V. Kannappan and R. Jaya Shanthi, Indian J. Pure Appl. Phys., 43, 750 (2005)
15. A.N. Kannappan and V. Rajendran, Indian J. Pure Appl. Phys., 30, 240 (1992).

16. M. Aravinthraj, S. Venkatesan and M. Kamaraj, Int. J. Chem. Environ. Pharm. Res., 2, 5 (2011).

17. S. Thirumaran and P. Thenmozhi, Asian J. Appl. Sci., 3, 153 (2010).

18. M.A. Saleh, S. Akthar, M.S. Ahmed and M.H. Uddin, Phys. Chem. Liq., 40, 635 (2002).

19. C. Franjo, M.T. Lorenzana, J.L. Legido, M.I. Paz Andrade and E. Jimenez, J. Chem. Thermodyn., 26, 1025 (1994).

20. J.L. Trenzado, J.S. Matos and R. Alcalde, Fluid Phase Equilib., 200, 295 (2002)

21. M.J. Souza, E. Jimenez, J.L. Legido, J. Fernandez, E. Perez-Martell and M.I. Paz Andrade, J. Chem. Thermodyn., 24, 119 (1992).

22. M. Haro, I. Gascon, P. Cea, C. Lafuente and F.M. Royo, J. Thermal Anal. Calorim., 79, 51 (2005).

23. P.S. Nikam and S.J. Kharat, J. Chem. Eng. Data, 50, 455 (2005).

24. J.B. Romans and C.R. Singleterry, Structural Guides to the Development of High Dielectric Constant Esters for Capacitors, Vol. 6, pp. 56-63 (1961). 